\title{
Impact of Opioid on Pain Management in Last Days of Life among Hospice Patients: A review
}

\author{
Nezar ASS ${ }^{1}$, Abdallah AK $^{2}$ and Nusairat A $^{3}$ \\ ${ }^{1}$ Dubai Hospital, The UEA \\ ${ }^{2}$ Faculty of Nursing, Psychiatric and Mental Health, The Hashemite University, Jordan \\ 3Jordanian Royal Medical Services, Jordan
}

\section{Introduction}

Palliative care is an approach that improves the quality of life of patients and their families facing the problem associated with lifethreatening illness, through the prevention and relief of suffering by means of early identification and impeccable assessment and treatment of pain and other problems, physical, psychosocial and spiritual (WHO, 2013). Hospice considered to be the model for quality, compassionate care for people facing a life-limiting illness or injury, hospice care involves a team-oriented approach to expert medical care, pain management, and emotional and spiritual support expressly tailored to the patient's needs and wishes. Support is provided to the patient's loved ones as well [1].

Pain is extremely common in patients with advanced cancer, with prevalence as high as $80 \%$ among palliative patients in last stages, the vast majority of patients with cancer pain require opioids for treatment [2]. Pain is widely prevalent in the last weeks of life regardless of the setting in which patients are being managed. As an example, one estimate suggests that at least one-fifth of the million patients who die in hospitals each year experienced pain during the final admission [3], a survey of palliative patients in nursing homes found that about $50 \%$ had daily pain, which was sever pain in about $85 \%$. Similarly, in a survey of Americans with terminal illness living at home, $50 \%$ had moderate to severe pain.

Pain management in populations with serious and advanced illness should be understood within a broader palliative care model. The concept of "total pain" recognizes that pain at the end of life encompasses more than the "physical" pain associated with the physical ravages of disease, and can include emotional, social, and spiritual aspects, Comprehensive pain assessment must include all these factors in an effort to understand the contribution of pain to suffering. As described a document known as the Consensus Project for Best Practices in Palliative Care, pain and symptom control is a key domain of palliative care but must be combined with other strategies in a broader approach to the patient with serious or life-threatening illness [4]. The setting in which patients receive end-of-life care strongly influences the extent to which pain management and the more comprehensive goals of palliative care can be pursued. Surveys indicate that most people would prefer to die at home, but the reality is that less than one-quarter of patients in the United States actually do. About 50\% die in the hospital and 25\% die in nursing homes or other long-term care facilities, although utilization of home hospice programs has increased, only $42 \%$ of Americans who die access hospice services and the median length of stay is only 20 days.

Pharmacotherapy is the mainstay of treatment for pain at the end of life. There are three broad categories of analgesic medications: opioids, non-opioid analgesics (including acetaminophen and the non-steroidal anti-inflammatory drugs), and the so-called adjuvant analgesics, which comprise numerous agents in diverse classes. Most adjuvant analgesics are commercially available for indications other than pain but are analgesic in specific circumstances $[5,6]$. The primary objective of the study is to assess the efficacy of opioid on patients suffering from cancer pain in last days to patients who had been admitted to palliative care units.

\section{Methodology}

In this review a comprehensive literature review was conducted using the electronic databases of CINAHL and Medline, PubMed, EPSCO, Science direct for articles published between 2007 to 2013 by using keywords: "palliative pain", "opioid effect", "hospice pain", "pain management among hospice". 50 articles were found after extensive searching via electronic database, eight articles that include inclusion criteria.

The inclusion criteria during searching were to meet following criteria:

- Investigate that hospice patients suffering from pain.

- Include palliative and hospice patient in End Stage of Life.

- Articles were written in English language.

- Research study.

After apply inclusion criteria eight articles selected between 2007 to 2013, most articles founded in Nursing Journal, [7] and title of articles revolved about pain management among hospice patients especially in last days of life. The articles were published in Nursing Journal in many countries, Singapore, Germany, Canada, United States, and United Kingdom.

\section{Methodological characteristics}

After extensive search in electronic database eight research articles conducted to this review, many method were used in articles, retrospective, quantitative, observational study, many tools and instrument used through the Ten articles related to cancer pain management in last days of life among hospice patients, but observational was most common used through articles $[8,9]$.

\section{Sample characteristics}

The sample size in ten studies were ranged between 58 to 238 cancer patients, most site of cancer among patients were in lung, brain,

*Corresponding author: Abdallah AK, Clinical instructor, Psychiatric and Mental Health, The Hashemite University, Jordan, Tel: 962772313135; E-mail: abu_keet@yahoo.com

Received February 25, 2016; Accepted June 01, 2016; Published June 09, 2016

Citation: Nezar ASS, Abdallah AK, Nusairat A (2016) Impact of Opioid on Pain Management in Last Days of Life among Hospice Patients: A review. Adv Practice Nurs 2:114. doi:10.4172/2573-0347.1000114

Copyright: @ 2016 Nezar ASS, et al. This is an open-access article distributed under the terms of the Creative Commons Attribution License, which permits unrestricted use, distribution, and reproduction in any medium, provided the original author and source are credited. 
colorectal, spinal and liver cancer. Variety ages in this study but almost of ages were above 50 and more both gender male and female but the majority were men, but there a study among children about age 7 and less, the sample that selected through articles from many countries Singapore, Germany, Canada, United States, Tanzania and United Kingdom.

\section{Result}

There are many evidences that proof effect of opioid on pain management among cancer patients and non-cancer patients, but the debate is what magnitude of effect of opioid on cancer pain management in last days of life, in other word after the cancer metastatic and spread to almost organs in the body can the opioid controlled over sever pain. In a study conducted in 2010 in Singapore, to Krishna, Poulose, and Tan, which the purpose of the study was to examine whether opioid use among terminally ill cancer patients during the last 2 days of life had any influence on pain, the study was retrospective review of case notes of patients who were diagnosed with terminal cancer and had passed away in a 95-bedded oncology ward between September 2006 and September 2007 was conducted, were 238 patients who received specialist palliative care, at 48 hours and 24 hours before death 187 (78.6\%) patients had received opioids in high dose, while 51 patients (21.4\%) received opioid in regular doses, the record revealed that group that had taken large doses less pain and controlled about $85 \%$ than other group, but that lead to aggravate other symptom like constipation, but less pain in last 48 hours before death.

More than $80 \%$ of the patients reported freedom from pain or only moderate pain during the opiate therapy. Among patients receiving opioids by the transdermal route there were significantly more frequent complaints of pain $(p=0.004)$ and nausea $(p=0.001)$. During the last days of life continuous subcutaneous infusions containing opiates facilitated good analgesia within an acceptable spectrum of sideeffects. Most problems with controlling symptoms in outpatients were encountered in younger patients $[10,11]$.

Another study conducted in Tanzania [6], which discussed effect of Morphine on pain among hospice patients the results also showed that intravenous morphine solution was the most common route (96\%) of administration. Fifty-seven percent of the patients described the doses of morphine given to be effective in relieving their pain. Although most patients $(79 \%)$ experienced morphine-induced side effects, the majority $(93 \%)$ were continuing with the therapy, the study revealed that the use of morphine is acceptable among a large proportion of patients receiving hospice care and the majority of them find the doses given effective to relieve their pain.

While an article publish in 2013, that case study to examine effect different doses of transdermal Fentanyl patch on pain control among last days of life among hospice patient, present 2 cases of palliative cancer patients, first patient who received transdermal Fentanyl at doses titrated up to 210 and $175 \mu \mathrm{g} / \mathrm{h}$, while the second patient received titrated to doses transdermal Fentanyl patch $>140 \mu \mathrm{g} / \mathrm{h}$, the patient that received titrated $210 \mu \mathrm{g} / \mathrm{h}$ reported less pain and provided adequate pain control and was well tolerated.

Salpeter, FACP, Buckley, Bruera [4] conducted a study in 2013, California, the purpose was to evaluate the efficacy of using verylow-dose methadone as the sole long-acting opioid agent in a hospice practice, which use retrospective, observational study of the use of methadone, which reviewed the records of 240 patients admitted to a community-based hospice from July 1, 2011 to April 1, 2012, with data collected until hospice discharge or until April 30, 2012, which were two group first hospice patients, while other group non cancer patient, the result revealed that the hospice patients received had a median reported pain score of 3 and a peak score of 7 , while in non-cancer patients reported pain score of 0 a peak score 3 in same dose of methadone, the conclusion of this study increase the dose of methadone is require to control the hospice patients.

Salas and Frasca conducted a randomized, double-blind, placebo controlled study in 2012, to study effect of ketamine and placebo on hospice patients, the result had shown that twenty patients were analyzed (11 received ketamine and 9 received placebo). Self-reported pain did not differ between the two groups, as the symptoms continued to evolve during the study period. The tolerance for ketamine was satisfactory; the study did not confirm the efficacy of the ketamine on control of hospice patients.

Zordan and Flynn [7] conducted study in 2011, to examine the last 3 days of life for the hospice patients, dying in a palliative care unit, for pain control, a retrospective review of medical records of consecutive patients who died in two inpatient palliative care units. Information collated included demographic and medical information, symptom data, and medications (opioids, benzodiazepines and antipsychotics) administered, One hundred five cases and 100 comparators were identified, morphine equivalents ( $82.8 v s .170 .5 \mathrm{mg}, \mathrm{p}<0.05)$, midazolam (12.1 vs. $19.1 \mathrm{mg}, \mathrm{p}<0.05)$, and lorazepam equivalents $(0.9$ vs. $2.4 \mathrm{mg}$, $\mathrm{p}<0.01$ ), based on the result the patients that received high doses of morphine, midazolam, lorazepam reported less pain than comparative group.

In another study among dying children conducted by [2], Retrospective chart review over a 7-year period (Jan 1998-Jan 2005) of PCA treated children dying of cancer was used, which study effect of patient-controlled analgesia PCA on pain controlled among dying children, the result revealed that eight children were on PCA for a median duration of 9 days (range, 1 to 50). The daily median intravenous morphine equivalent dose referenced to body weight increased significantly when PCA was initiated and during the last week of life. In the last week of life, the median daily number of delivered and undelivered bolus requests ranged from 7.5-21 and 0-4.5, respectively. To meet children's individual needs, 39 PCA parameter changes on 22 opportunities were performed. Median daily mean pain scores remained low (range, $0-3$; numerical rating scale $0-10$ ) throughout the period.

\section{Conclusion}

The review revealed that the use of opioid is acceptable among a large proportion among terminally ill cancer patients during the last days of life, and that the majority of them find the doses given effective to relieve their pain, but the result shown that small doses of opioid didn't effect on pain controlled, large doses is require to achieve desirable goals to pain management. Other point that results showed that opioids are safe medications for symptom alleviation in terminally ill cancer patients during the last days of life and have no deleterious influence on survival, but they have to management the symptom that result from high dose of opioid.

\section{References}

1. Krishna R, Poulose J, Tan B, Goh C (2010) Opioid Use amongst Cancer Patients at the End of Life. J Pain Symptom Manage 34: 1-3.

2. Schiessl C, Gravou C, Zernikow B, Sittl R, Griessinger N (2008)Use of patientcontrolled analgesia for pain control in dying children. Support Care Cancer 16: $531-536$. 
Citation: Nezar ASS, Abdallah AK, Nusairat A (2016) Impact of Opioid on Pain Management in Last Days of Life among Hospice Patients: A review. Adv Practice Nurs 2:114. doi:10.4172/2573-0347.1000114

Page 3 of 3

3. Clement PMJ, Beuliclienk B, Beek K, Mertens B, Menten J (2013) The Use of High Dosages of Transdermal Buprenorphine for Pain Management in Palliative Cancer Patients: A Case Study. Case Rep Oncol 6: 169-173.

4. Salpeter S, Buckley J, Bruera E (2013) The Use of Very-Low-Dose Methadone for Palliative Pain control and the prevention of opioid hyperalgesia. J Palliat Med 16: 616-622.

5. Kissin I, Bright CA, Bradley EL (2012) Ketamine Analgesic Effect by Continuous Intravenous Infusion in Refractory Cancer Pain: Considerations about the Clinical Research in Palliative Care. Anesth Analg 91:1483-1488.

6. Kamuhaba A, Jezekil D (2009) Rational use and effectiveness of morphine in the palliative care of cancer patients at the Ocean Road Cancer Institute in Dar es salaam, Tanzania. Tanzan J Health Res 11: 170-174.
7. Rashidi NM, Zordan RD, Flynn E, Philip JA (2011) The Care of the Very Old in the Last Three Days of Life. J Palliat Med 14: 1339-1344.

8. Costantini M, Ripamonti C, Beccaro M, Montella M, Borgia P, et al. (2011) Prescription patterns of analgesics in the last 3 months of life Ann Oncol 20: 729-735.

9. http://www.who.int/cancer/palliative/definition/en/

10. http://www.Hospice/Care/National/Hospice/and/Palliative/Care/Organization.mht

11. Maier R, Maier A, Müller-Busch C (2008) Outpatient opiate therapy in cancer patients during their last days of life. Schmerz 22: 148, 150-155. 